OPEN ACCESS

Edited by:

Olinga Taeed,

Centre for Citizenship, Enterprise and Governance, United Kingdom

Reviewed by:

Natalie Pankova

Metadvice Ltd, United Kingdom Jonathan M. Fuchs, The Kidder Street Consulting Group, United States

*Correspondence: Jens Ducrée jens.ducree@dcu.ie

Specialty section This article was submitted to Blockchain for Science, a section of the journal

Frontiers in Blockchain

Received: 23 July 2020 Accepted: 23 September 2020 Published: 19 November 2020

Citation:

Ducrée J, Gravitt M, Walshe R, Bartling S, Etzrodt $M$ and Harrington T (2020) Open Platform Concept for Blockchain-Enabled Crowdsourcing of Technology Development and Supply Chains. Front. Blockchain 3:586525.

doi: 10.3389/fbloc.2020.586525

\section{Open Platform Concept for Blockchain-Enabled Crowdsourcing of Technology Development and Supply Chains}

\author{
Jens Ducrée ${ }^{1 *}$, Max Gravitt ${ }^{2}$, Ray Walshe ${ }^{3}$, Sönke Bartling ${ }^{4}$, Martin Etzrodt ${ }^{5}$ and \\ Tomás Harrington ${ }^{6}$ \\ ${ }^{1}$ School of Physical Sciences, Faculty of Science \& Health, Dublin City University, Dublin, Ireland, ${ }^{2}$ Digital Scarcity, \\ Digitalscarcity.io, United States, ${ }^{3}$ School of Computing, Dublin City University, Dublin, Ireland, ${ }^{4}$ Blockchain for Science, \\ Berlin, Germany, ${ }^{5}$ Akasha Foundation, Zug, Switzerland, ${ }^{6}$ Innovation, Technology \& Operations Management Group, \\ Norwich Business School, Faculty of Social Sciences, University of East Anglia, Norwich, United Kingdom
}

We outline the concept of an open technology platform that builds upon a publicly accessible library of fluidic designs, manufacturing processes, and experimental characterization, as well as virtualization by a "digital twin" based on modeling, simulation, and cloud computing. Backed by the rapidly emerging Web3 technology "Blockchain," we significantly extend traditional approaches to effectively incentivize broader participation by an interdisciplinary "value network" of diverse players. Ranging from skilled individuals (the "citizen scientist" and the "garage entrepreneur") and more established research institutions to companies with their infrastructures, equipment, and services, the novel platform approach enables all stakeholders to jointly contribute to value creation along more decentralized supply chain designs including research and technology development (RTD). A blockchain-enabled token economy efficiently leverages the "Wisdom of the Crowds" and secures "trust" and transparency by reputation systems requiring "skin in the game" from contributors. Prediction markets are created for guiding decision making, planning, and allocation of funding; competitive parallelization of work and its validation from independent participants substantially enhances quality, credibility, and speed of project outcomes in the real world along the entire path from RTD, fabrication, and testing to eventual commercialization. This novel, Blockchain-backed, open platform concept can be led by a corporation, academic entity, a loosely organized group, or even "chieflessly" within a smart-contract encoded Decentralized Autonomous Organization (DAO). The proposed strategy is particularly attractive for highly interdisciplinary fields like microfluidic Lab-on-a-Chip systems in the context of manifold applications in the Life Sciences. As an exemplar, we outline the centrifugal "Lab-on-a-Disc" technology. Rather than engaging in all sub-disciplines themselves, many smaller, highly innovative actors can focus on strengthening the product component distinguishing their unique selling point (USP), e.g., a particular bioassay, detection scheme, or application scenario. In this effort, system integrators access underlying commons like fluidic design, manufacture, instrumentation, and software from a more resilient and diversified supply chain, e.g., based on a verified pool of community-endorsed or certified providers.

Keywords: technology platform, supply chain, value creation, crowdsourcing, competitive parallelisation, microfluidics, validation 


\section{INTRODUCTION}

It is now widely recognized that manufacturing "value chains," including initial design, testing, and optimization stages, to production ramp-up and in-use activities are critical in transforming new technologies and ideas into marketable products. However, how best to manage critical network resources in the design and setup of enabling (yet often) "nascent" supply chains is poorly understood and executed. Forming and growing a "resilient" supply chain should be a critical component in the design of a platform-based business model.

In such platform-based strategies that have been widely adopted by mature industries like automotive since the latter part of the 1970s (Muffatto, 1999), a wide range of products are derived from a joint, modular architecture so components, processes, and services can be shared internally and/or with suppliers. Such streamlined approaches accelerate, de-risk, and reduce costs for research and technology development (RTD), and subsequent manufacture and configurability of new products; related formal or internal standards also allow forging comprehensive RTD capabilities and supply chains composed of specialist players as a hallmark of modern, task-sharing economies. The availability of a critical market size and diversity of its members constitutes a key prerequisite for such platform strategies; otherwise, the setup cost for such a generalized approach would be excessive, the risk high, and, hence, the overall incentive for (independent) parties to embark rather low.

The distributed ledger technology (DLT) "Blockchain" (Nakamoto, 2009; Yaga et al., 2018) has already proven to afford a high level of trust and transparency to financial transactions for fueling collaboration in the digital world; its "smart contracts" are mostly executed on the [nearly (Miller, 2016)] Turing-complete "Ethereum Virtual Machine" (EVM) (Buterin, 2014) without the need for a middleman. Beyond blockbuster Bitcoin and decentralized finance ("DeFi"), our new approach expands the concept of Blockchain-endowed trust to the real world of product development for crowdsourcing of work, expertise, infrastructure, forecasting, and services along the entire pipeline from idea generation, funding, RTD, and production and marketing.

By competitive parallelization of work and their validation, our novel concept resorts to "Wisdom of the Crowds" (Surowiecki, 2004; Becker, 2010; Hill and Ready-Campbell,

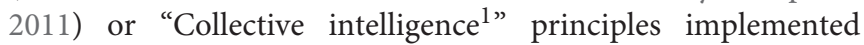
by Blockchain, typically Ethereum-enabled bounty networks ${ }^{2}$ Networks ${ }^{3}$ and prediction markets ${ }^{4,5,6}$ (Halton, 2019) for finding best possible "truth" as a solid foundation of governance and decision making, as well as assessment of technical progress

\footnotetext{
${ }^{1}$ Collective Intelligence. Available online at: https://en.wikipedia.org/wiki/ Collective_intelligence

${ }^{2}$ Bounty0x (2019). Available online at: https://bounty0x.io/ (accessed July 27, 2020).

${ }^{3}$ The Bounties Network (2019). Available online at: https://www.bounties. network/

${ }^{4}$ Augur - Available online at: https://www.augur.net/ (accessed July 24, 2020).

${ }^{5}$ Sightpm (2020). Available online at: https://sight.pm/ (accessed July 27, 2020).

${ }^{6}$ StormXio (2020). Available online at: https://stormx.io/ (accessed July 27, 2020).
}

and future, technological, or commercial prospects, e.g., returnon-investment. This comprehensive crowdsourcing strongly relies on a token economy employing well-established "skin in the game" mechanisms like proof-of-work (PoW), proofof-stake (PoS), formalized reputation, staking, governance, and $\operatorname{arbitration}^{7,8}$ schemes. Funding can be leveraged through blockchain-based seigniorage ${ }^{9}$ as well as recently proposed crowdfunding (Edmondson, 2020) ${ }^{10}$, initial coin/security/token offerings (ICOs/STOs/ITOs), curation markets (de la Rouviere, 2017; Rouviere, 2017), and token bonding curves (TBCs) (Goro, 2018).

Among the wide scope of applications, this paper exemplifies the implementation and benefits of the novel, blockchainbacked open platform concept for "Lab-on-a-Chip" systems. The primary commercial use cases of these microfluidic devices are biomedical in vitro diagnostics (IVD) at the point-of-care (PoC), tools for life-science (research), monitoring industrial processes, infrastructures, and the environment. The present global market for such microfluidic devices and products is valued well above 10 billion USD (Status of the Microfluidics Industry, 2019).

Conventional platform concepts (Ducrée and Zengerle, 2004) and standards (Klapperich, 2009; Stavis, 2012; van Heeren, 2012; Tantra et al., 2016; Reyes et al., under review) have already been suggested for such Lab-on-a-Chip systems. However, the vast majority of these microfluidics-based products still addresses comparatively small niche markets for which it is extremely hard to leverage economy-of-scale effects to recover upfront investment, e.g., for setting up RTD and production; nevertheless, companies are still quite hesitant to share their technology portfolio outside their own contract suppliers.

This paper first outlines the basics of open platform models for the representative case of the modular, centrifugal microfluidic "Lab-on-a-Disc" (LoaD) platform. It then elaborates present bottlenecks for wider-scale commercial success of this special variant of Lab-on-a-Chip technology. Next, "Wisdom of the Crowd" mechanisms in connection with their blockchainbased implementation powered by crypto-economically enabled reputation schemes ${ }^{11}$ are elaborated. With the final summary, we discuss further synergies, opportunity, and challenges.

\section{PLATFORMS}

Technology platforms create a variety of applications, e.g., to address different market segments, from a common set of design rules, materials, processes, components, and development tools. Prominent examples are car platforms (e.g., Volkswagen Group, Toyota, GM, Fiat, Mitsubishi, Ford, Mazda, Chrysler, Hyundai-Kia) defining essential architecture such as floorplan, wheelbase, steering mechanism, suspensions, and wheelbase ${ }^{12}$. Economy-of-scale effects markedly reduce

\footnotetext{
${ }^{7}$ COLONY.io. Available online at: https://colony.io/ (accessed July 24, 2020).

${ }^{8}$ Aragon (2020). Available online at: https://aragon.org/ (accessed July 24, 2020).

${ }^{9}$ Seigniorage. Available from: https://en.wikipedia.org/wiki/Seigniorage

${ }^{10}$ Gitcoin. Available online at: https://gitcoin.co/ (accessed July 24, 2020).

${ }^{11}$ Reputation System. Available online at: https://en.wikipedia.org/wiki/ Reputation_system (accessed August 28, 2020).

${ }^{12}$ Car Platform. Available online at: https://en.wikipedia.org/wiki/Car_platform
} 
cost (per unit) of RTD for the product and production technologies, and lower the number of parts in the inventory, promote quality, enhance reliability, enable customization, and facilitate logistics. Computing platforms provide an environment for executing programs; there are different levels, such as browsers, program suites, operating systems, software, hardware, and combinations thereof ${ }^{13}$ (Böttcher, 2018).

In strictly proprietary platforms, these core elements are sourced internally, or from designated contract suppliers who are bound to confidentiality and/or exclusivity. This restrictive policy can be lifted by publishing standards, e.g., for component interfaces or test methods, to attract more players and thus to create choice for buyers and to relax the dependence of specialized suppliers from a single organization; yet, certain key enabling intellectual property (IP) including know-how may remain confidential, e.g., kept as a trade secret by an internal group or filed as patent, to shield the product against competition. In any case, the formation of such platforms vitally requires the involvement of a critical mass of participants and a matching market demand. Therefore, it is much easier for established, large-scale industries and their conglomerates to organize a "closed" supply chain.

Open platforms release information needed to participate in the RTD and supply chain to pro-actively stimulate the engagement of multiple parties, thus inducing crucial economyof-scale effects for seminally augmenting quality, speed, and cost. Especially smaller, highly innovative system integrators can thus efficiently outsource essential elements, such as materials, manufacture, and specialized services, to a commercial network while leaving sufficient room to distinguish their own value proposition and USPs, e.g., their distinctive methods or application spaces. The benefits of such open platform approaches are likely to significantly outweigh drawbacks such as loss of IP on common aspects of the product that may be shared with competitors.

\section{EXAMPLE: LAB-ON-A-DISC}

\section{Technology}

In the wide arena of microfluidic systems, platform concepts (Ducrée and Zengerle, 2004) and related standards (Klapperich, 2009; Stavis, 2012; van Heeren, 2012; Tantra et al., 2016; Reyes et al., under review) have been propagated for quite a while. Applications are mostly found in the context of the life sciences, in particular for sample-to-answer systems for biomedical point-of-care and global diagnostics, liquid handling automation, process analytical techniques, and cell line development for biopharma as well as monitoring the environment, infrastructure, industrial processes, and agrifood. In the context of global virus outbreaks, Lab-on-a-Chip systems have been developed for rapid patient screening, e.g., in the context of the current Covid-19 pandemic (McRae et al., 2020; Tymm et al., 2020; Zhuang et al., 2020).

To further illustrate the extended, open platform concept presented in this paper, we consider the specific use case of centrifugal microfluidic systems that have been developed by many commercially ${ }^{13,14,15,16,17}$ and academically (Schembri et al., 1992, 1995; Madou and Kellogg, 1998; Johnson et al., 2001; Honda et al., 2005; Andersson et al., 2007; Clime et al., 2015, 2019; Malic et al., 2015; Thompson et al., 2016; Krauss et al., 2019) driven initiatives since the 1990s. On these LoaD systems (Figure 1), liquid samples and reagents are pumped and conditioned by a centrifugal field that is modulated by the spin rate of the rotor. While a variety of geometrical formats of microfluidic chips that display a network of miniaturized chambers and interconnecting channels have been utilized, a disc of similar size as optical storage media (e.g., CD, DVD, or Blu-Ray) is still a common shape.

Its exceptional capability of larger-scale (functional) integration (LSI) on the LoaD enables comprehensive sampleto-answer automation and parallelization for "point-of-use" scenarios as a critical USP with major markets in bioanalytical point-of-care diagnostics, tools for life-science research, and the biopharmaceutical industry. A "White Paper"-type document is currently issued as a foundational element to encourage and enable broad participation of RTD communities and supply chains. In particular, "digital twin" concepts (Grieves and Digital, 2017) in connection with widely available cloud computing will shift the emphasis from experimental to in silico design optimization, and thus massively open up participation in crowdsourcing of RTD.

Modularity, whether by hardware or design, constitutes a key enabler for platform strategies. On a component level, the LoaD features an instrument that is essentially assembled from a simple spindle motor, electronic control, and (mostly optical) detection units; this "player" receives a typically singleuse (polymer) cartridge that fully contains the sample and reagents, while safely retaining potentially (bio-)hazardous waste; the contact-free, rotationally induced pressurization of the chipbased liquids supersedes the need for maintenance-prone fluidic or pneumatic interfaces to the player. The variant of the LoaD platforms considered here (Ducrée et al., 2007; Steigert et al., 2007; Böning et al., 2008; Mark et al., 2009; GarcíaCordero et al., 2010; Godino et al., 2012; Gorkin et al., 2012; Dimov et al., 2014; Kinahan et al., 2014, 2015, 2016; Burger et al., 2015; Mishra et al., 2015; Brennan et al., 2017; Delgado et al., 2018) also allows a second level of modularization where assay protocols are run in a batch-wise "stop-and-go" fashion along a sequence of Laboratory Unit Operations (LUOs), such as metering, mixing, and particle filtering, each of which is independently controlled by a rotationally actuated, normally closed valve at its interconnecting outlet.

Similar to common lumped-element models for electronic circuitry, a layout can be well-represented by a network of parallel

\footnotetext{
${ }^{13}$ Abaxis. Available online at: https://www.abaxis.com/

${ }^{14}$ Gyros Protein Technologies. Available online at: https://www. gyrosproteintechnologies.com/

${ }^{15}$ Blusense Diagnostics. Available online at: https://blusense-diagnostics.com/

${ }^{16}$ LaMotte Chemical Products Co. Available online at: https://www.lamotte.com

${ }^{17}$ Biosurfit (2020). Available online at: https://www.biosurfit.com/
} 

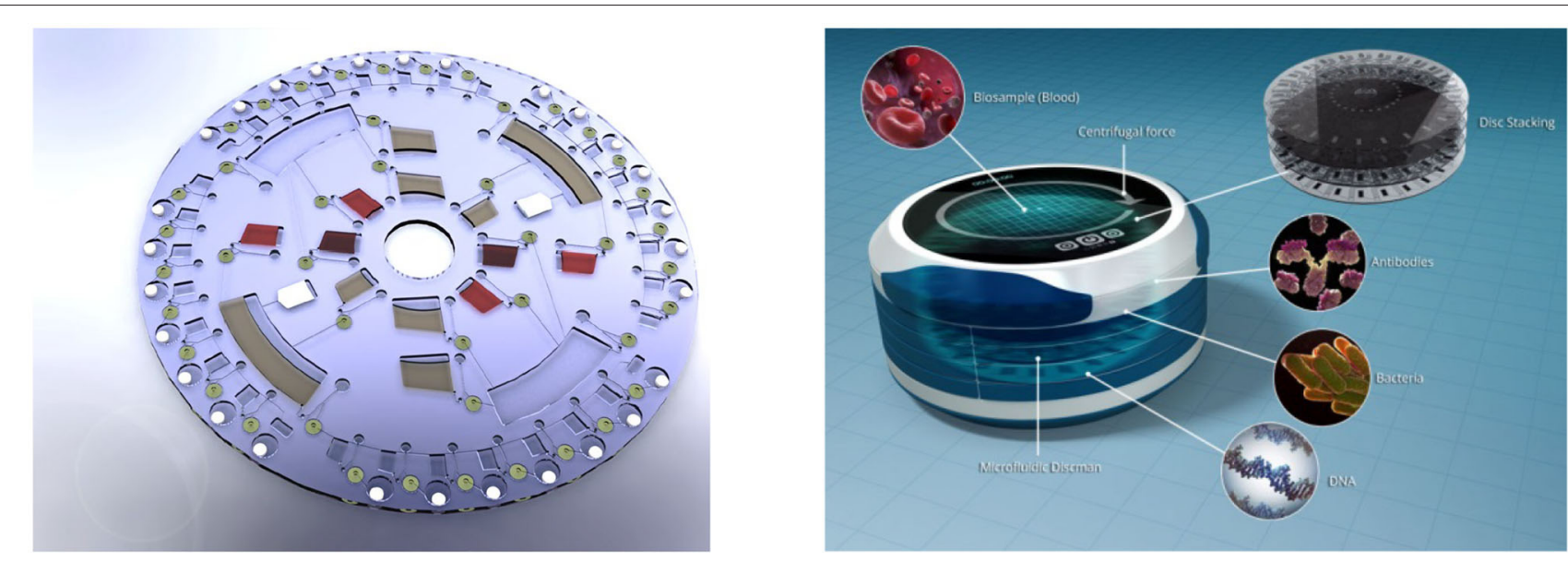

FIGURE 1 | Lab-on-a-Disc (LoaD) systems feature a modular setup of a single-use, polymer chip, often of similar geometry as common optical storage media like CD, DVD, or Blu-ray, which features a network of chambers for batch-wise conditioning of (bio-)samples and reagents. These chambers represent Laboratory Units Operations (LUOs) such as metering, mixing, aliquoting, purification, concentration, and particle separation, which are sequentially processed in a batch-wise fashion along a conventional laboratory protocol through normally closed valves placed at their interconnecting channels.

or serially connected fluidic equivalents of resistors, capacitors, inductances, diodes, relays, and routers that are powered by voltage or current sources. By virtue of their functionally modular architecture, LoaD systems can hence be described and simulated by lumped-element models where LUOs and valves are characterized by reduced-dimension transfer functions. Importantly, the availability of accurate modeling of liquid handling on the LoaD allows one to directly derive component performance and reliability from geometrical tolerances related to device manufacture to rapidly raise Technology Readiness Levels (TRLs) (Ducrée, 2020).

The modular setup and predictability of fluidic function from basic manufacturing tolerances creates a sound basis for crowdsourcing of RTD. In addition, and similar to mature industries such as electronics and Micro Electro Mechanical Systems (MEMS), capable supply chains can be built around foundries to significantly accelerate, de-risk, and economize the development of new applications.

\section{Supply Chain}

With modularity of its foundational technologies and scope applications, LoaD systems are particularly amenable to the platform concept. However, in line with other emerging industry-type examples, e.g., "plastic electronics," that are often characterized by new and innovative manufacturing processes driven by individual actors and new enterprises (Harrington and Srai, 2016), single-handed development is still prevalent among start-up companies in the arena of microfluidics.

Given the specialist nature and a limited pool of suppliers in terms of, e.g., specialized manufacture, the current modus operandi is to carry out contract work under strict confidentiality or exclusivity arrangements. As well as failing to take advantage of technological synergies and economies-of-scale, the underlying risk is that one becomes merely "reactive" in response to competitor strategies (Santos and Eisenhardt, 2009; Hills and Sarin, 2015). In the absence of widely accepted standards, a platform-based mechanism paired with blockchain-enabled incentivization schemes presented here can boost market driving strategies where an actor or enterprise may proactively influence the competitive landscape and industry standards (Jaworski et al., 2000; Kumar et al., 2000).

Concerns on sharing IP and trade secrets have been addressed by blockchain-enabled refined data management and also by permissioned (Singh, 2019), e.g., federated or consortium, blockchains ${ }^{18,19}$, which add a control layer to restrict access and participation. The legacy corporate culture is also rooted in the huge variety of underlying microfluidic concepts, often requiring development from scratch for most of their technological constituents. Actors and small emerging firms then focus their efforts on resolving associated technical issues and developing prototypes while early "non-technical" requirements are often overlooked.

As a result, research in the area of emerging industries has typically concentrated on the technology side, coupled with particular technology-specific commercialization challenges. However, the "industrial ecosystem" is much more complex, and cannot be readily described by a single viewpoint (Harrington and Zhang, 2017). For example, it is argued that emergence is largely dependent on the parallel development of a "new" supply chain or network to flank such commercialization activities (Sebastiao and Golicic, 2008). Yet, the design, setup, and operation of enabling supply chains, in the context of emerging industries, is poorly understood. One key challenge is the lack of a defined strategy that a firm can follow due to the uncertainty,

\footnotetext{
${ }^{18}$ IBM Blockchain's Hyperledger Fabric. Available online at: https://www.ibm. com/blockchain/hyperledger (accessed July 24, 2020).

${ }^{19}$ R3's Corda (2020). Available online at: http://www.r3.com (accessed July 20, 2020).
} 


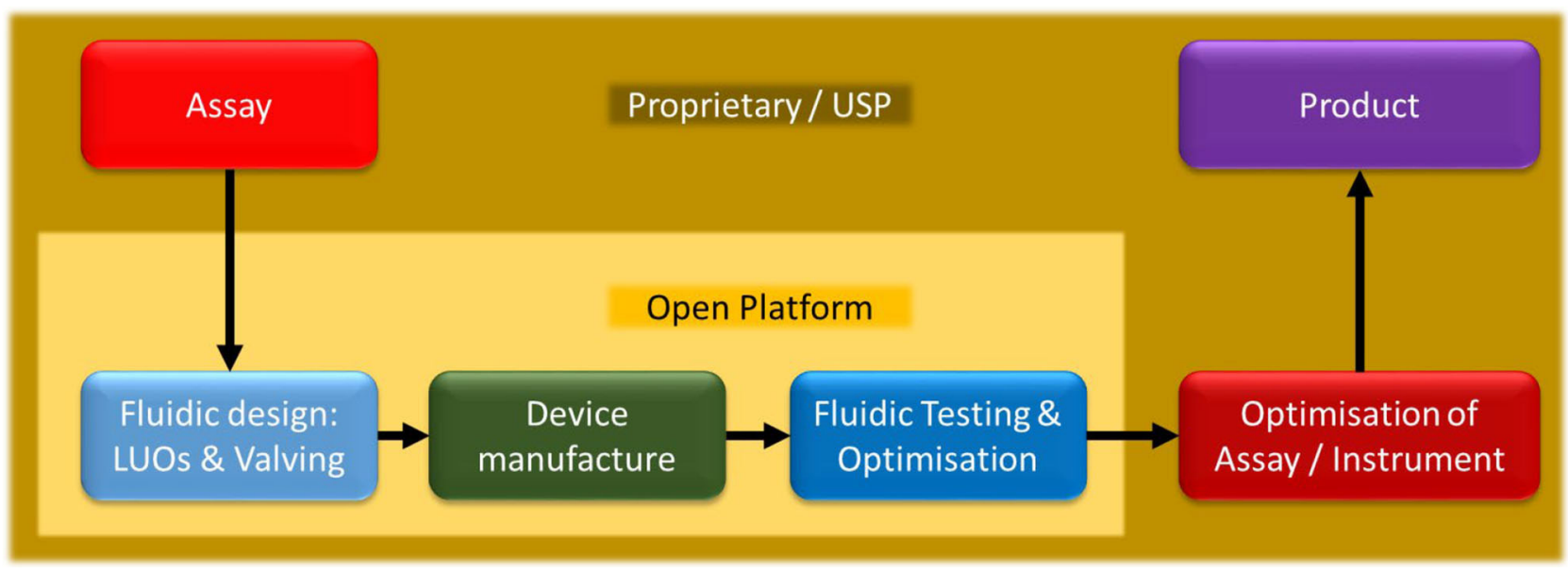

FIGURE 2 | Exemplary pipeline from idea to a unique microfluidic, e.g., "Lab-on-a-Disc" product. The proprietary part underpinning the Unique Selling Points (USPs) comprises of the original idea of an assay protocol, its reagents, or application including specific optimization cost, performance, productization, and marketing; the embedded, shared part comprises of a library of fluidic designs, testing, and manufacturing methods that are sourced from a common, multi-party RTD and supply chain, e.g., following foundry-type business models that are, for instance, well-proven in the electronics/MEMS (Ersland and Somisetty, 2012$)^{15}$ or photonics (Khan et al., 2019) industries.

which often forces entrepreneurs to experiment with multiple choices for supply chain designs (Sarasvathy, 2001).

For example, supplier identification has both a longand short-term impact on supplier selection and the performance of entire supply chains (Lasch et al., 2005). This selection process can be very time-consuming-leading to increased time-to-market and making it difficult to maintain (or achieve) critical "first mover advantage" (Sarasvathy, 2001). Consequently, identification and compilation of an appropriate pool of trusted suppliers have become an integral part of the supplier selection process (Govindan et al., 2018).

The proposed open platform concept can contribute to improve management of critical network resources in the setup of enabling "nascent" supply chains and allow system integrators to access shared assets (e.g., fluidic design, manufacture, instrumentation, and software) from more resilient supply chain setups (a verified pool of certified suppliers enabled by an open platform concept).

Even though there have been significant success stories in the world of microfluidic technologies, many projects are smothered by completely underestimated costs of bespoke facilities for (manufacturing) scale-up; it is typically only realized in retrospect that greater numbers of microfluidic devices, ideally produced by the eventual mass fabrication scheme, are required well before eventual market entry to optimize and properly validate functional reliability with sound statistics and consistent assay performance toward passing internal quality checks and regulatory compliance (Ducrée, 2019).

Figure 2 depicts a concept how an open platform can distribute the development and scale-up fabrication of LoaD technologies based on a supply chain for providing commons like fluidic design, manufacture, and testing. Similar to successful business structures in big industries such as electronics,
MEMS (Ersland and Somisetty, 2012) ${ }^{20}$ or photonics (Khan et al., 2019), this model is likely to stimulate the formation of foundries that provide digital-twin supported designfor-manufacture (DfM) for delivering highly predictable functionality of components and devices. The responsibility for such "commons" is thus taken from the shoulders of innovative system integrators who can align their resources on progressing their ring-fenced competitive edge, e.g., on behalf of their distinctive know-how on bioassays or their applications and market access.

\section{"WISDOM OF THE CROWDS"}

The idea that collective intelligence tends to supersede the quality of individual assessment was pushed since the early 2000s (Surowiecki, 2004). This section reviews instances where "Wisdom of the Crowds" principles have been successfully applied in the social Web2.0 and science to pave the way for its implementation for crowdsourcing of work, expertise, infrastructure, and services for RTD projects in the next section on related blockchain technologies.

\section{Social Web}

Already in the social Web 2.0, "wisdom of the crowds" has been extensively implemented, e.g., in social media (e.g., "likes," "followers") and online shopping (e.g., ratings and comments by buyers and sellers), which, as a positive knock-on effect, also boost customer engagement (Yoon and Youn, 2016; Tan et al., 2017). Especially in dearth of other objective sources, information obtained from the crowd can be very useful, and many portals have managed to widely suppress manipulation. For instance,

\footnotetext{
${ }^{20}$ List of MEMS foundries. Available online at: https://en.wikipedia.org/wiki/ List_of_MEMS_foundries
} 
tapping into the crowd has also proven to be very useful for aggregating information on the "state of the world," e.g., real-time updates on transport networks or footfall in local shops; even emerging pandemics such as Covid-19 have been identified and reported at a very early stage ${ }^{21}$ (Brownstein and Freifeld, 2007; McKenna, 2020).

\section{Finding "Truth" in Science and RTD}

The need for decision making in absence of "absolute truth" particularly applies to the realm of projects in science and RTD, which coarsely follow a sequence of conception, planning, evaluation, implementation, and exploitation. In principle, all these phases are susceptible to subjectivism, misjudgement, undeliberate error, and even deceit, whether from the originators or their assessors. Here, we briefly survey truth finding schemes for projects in the commercial and academic domains, which will then be ported to Blockchain in the subsequent section.

In the corporate world, RTD is often carried out within a closed circle of workers, managers and assessors (Figure 3 ). The technological idea or application case is based on an (assumed) understanding of a functional principle or market context. With the funding raised, staff is hired and resources for product development and its commercial exploitation procured, which is monitored by the stakeholders and boards appointed by them. Truth finding at the root of decision making is thus based by "skin in the game" of investors, management, and employees, e.g., in terms of assets, stock options, career opportunities, or salaries.

In science, a panel of uninvolved peers evaluates the proposal, its implementation plan, and the appropriateness of requested funding. Upon their positive review, a designated group of (internal) researchers, e.g., recruited from a closed research group or consortium, runs the project and disseminates its outcomes within the scientific community.

Transparent documentation of materials, methods, and results is at the heart of finding "truth" in academic publishing (Baldwin, 2018), where a two-stage process is usually enacted: upon submission, journal editors appoint independent experts to assess the quality and originality of the manuscript. Post acceptance, the entire scientific community is invited to validate the paper, so flawed or fabricated results are quickly disguised, especially on topics of wider-ranging relevance. Other than in the commercial world, errors mainly affect scholarly reputation rather than leading to financial penalties, so that legal sanctions are mostly enforced for gross misconduct or deliberate fraud. Compared to the commercial RTD path displayed in Figure 2, primarily the validation stage is crowdsourced in academia.

\section{BLOCKCHAIN TOOLBOX}

Having its origin in the first popular cryptocurrency Bitcoin launched by the famous white paper authored in 2009 by the pseudonymous individual or group "Satoshi Nakamoto" (Nakamoto, 2009; Sharma, 2019), blockchain technology

${ }^{21}$ HealthMap. Available online at: http://www.diseasedaily.org/about (accessed July 24, 2020). has already impressively succeeded to implement financial transactions on its cryptographically safeguarded DLT. Boosted a few years later by the release of EVM (Buterin, 2014), which can execute smart contracts, a plethora of projects continue to break new grounds in "DeFi" (Leonhard, 2019). Opinions of investors on the solidity and prospects of "crypto" tend to largely diverge (Suberg, 2020).

A broad range of commercial projects on advancing blockchain technologies are driven by companies and foundations $^{14,22}$ (see text footnote ${ }^{16,23}$ ); even more, projects pursuing goals that are shared by communities, referred to as "Commons," are carried out by a diverse range of loosely organized groups of volunteers. Management, governance and arbitration are enacted by a blockchain-backed token economy for stake-based decision making ${ }^{8}$. In the same spirit as permissionless access and decentralization, the blockchain community also seeks to extend the trust without middleman community to encode entire Decentralized Autonomous Organizations (DAOs) in smart contracts. These "DAOs"8,24,25,26,27,28,29 (Vigna, 2016) bear great promise to (self-) organize conception, fundraising, selection, management, monitoring, and governance.

As a key advantage, Blockchain supports funding of projects by seigniorage (Craig and Kachovec, 2019), or the privilege to issue new money, typically in the form of project-specific initial coin offerings (ICO), which issue asset tokens ${ }^{30}$ that may be traded against other crypto- or fiat currencies at various exchanges, or for other purposes such as voting rights in liquiddemocracy governance ${ }^{31}$ or for settling blockchain utility fees. Yet, there are still some regulatory issues to be addressed ${ }^{32}$.

In the realm of science and RTD, several blockchain portals already support scientific publishing ${ }^{33,34}$ as well as RTD $^{35}$ (Bartling, 2016). Blockchain tools have been developed for aggregating and exchanging data on the state of the world, e.g., obtained from simulation, historical records,

\footnotetext{
${ }^{22}$ AKASHA RELOADED. Available online at: https://akasha.world/

${ }^{23}$ Hyperledger (2020). Available online at: https://www.hyperledger.org/ (accessed July 24, 2020).

${ }^{24}$ DAOstack. Available online at: https://daostack.io/ (accessed August 17, 2020).

${ }^{25}$ The Genesis DAO. Available online at: https://daostack.io/genesis (accessed August 18, 2020). doi: 10.4000/genesis.834

${ }^{26}$ The Maker Protocol. Available online at: https://makerdao.com/en/whitepaper (accessed July 24, 2020).

${ }^{27}$ DAOfest. Available online at: https://www.daofest.io/ (accessed August 17, 2020).

${ }^{28}$ New GBA (2020). Available online at: https://www.gbaglobal.org/governance (accessed July 24, 2020).

${ }^{29}$ Moloch (2019). Available online at: https://concourseopen.com/blog/molochdao-explained/ (accessed August 18, 2020).

${ }^{30}$ ERC-20 Tokens, Explained. Available online at: https://cointelegraph.com/ explained/erc-20-tokens-explained

${ }^{31}$ Liquid Democracy. Available online at: https://en.wikipedia.org/wiki/ Liquid_democracy (accessed August 12, 2020).

${ }^{32}$ SEC (2017). Available online at: https://www.sec.gov/news/press-release/2017131 (accessed July 24, 2020).

${ }^{33}$ ARTiFACTS. Accelerated. Available online at: https://artifacts.ai/ (accessed July 24, 2020).

${ }^{34}$ Bloxberg. Available online at: https://bloxberg.org/ (accessed July 24, 2020).

${ }^{35}$ DEIP.world. Available online at: https://deip.world/ (accessed July 24, 2020).
} 


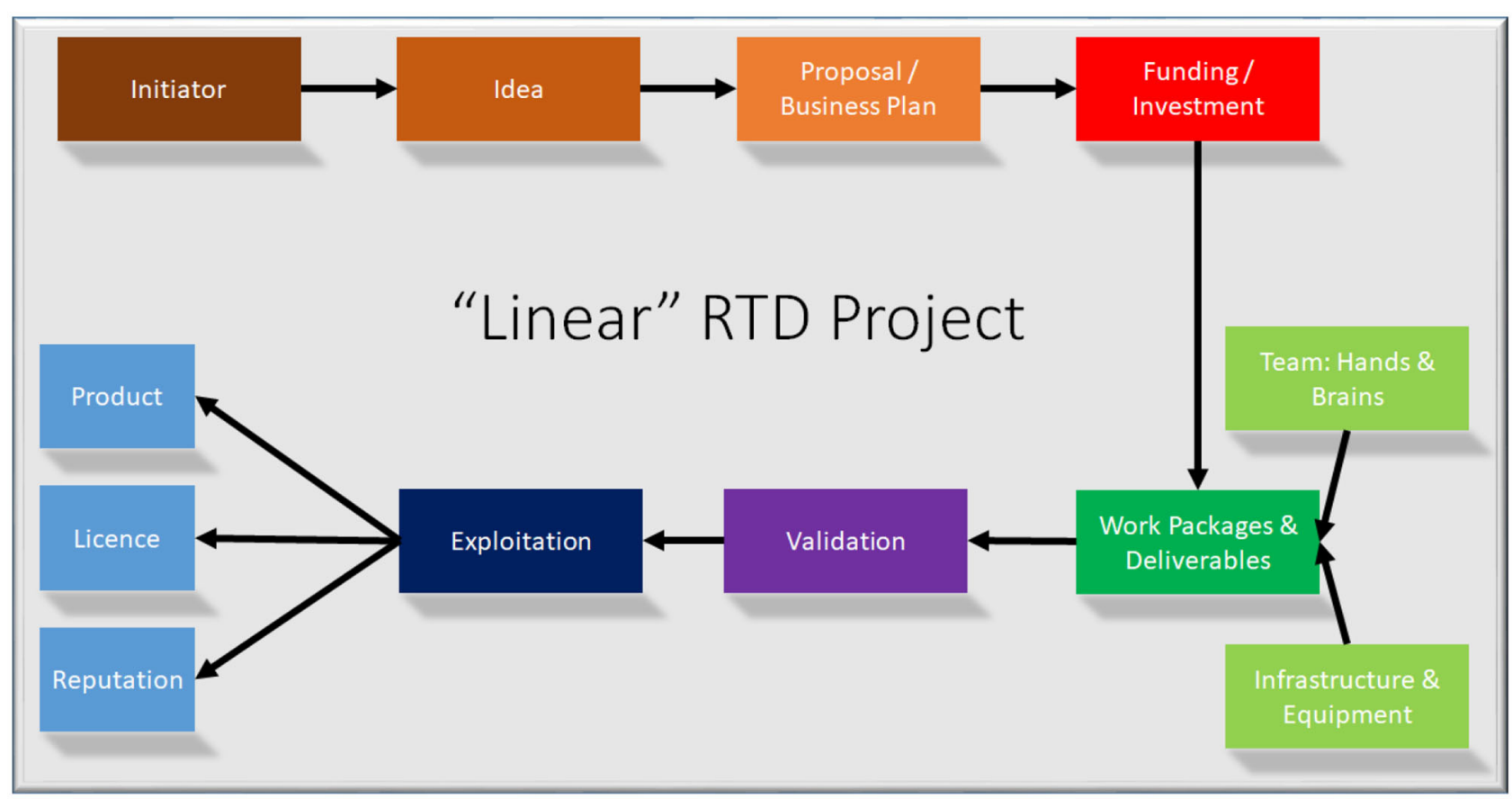

FIGURE 3 | Projects are traditionally organized in a linear fashion from starting with idea creation, advancement into a business plan, and attracting funding. Teams and their infrastructures are set up to execute work packages (WPs) that they (self-) validate. The results are then exploited through various avenues, e.g., by direct sales of a product, by licensing, or, in particular in academia, by publishing for building up reputation in the community.

and "Internet of Things (IoT)" sensor networks ${ }^{36,37}$. Also, non-fungible tokens (NFTs) ${ }^{38}$ (Montoya, 2020) have been proposed to protect intellectual ownership, e.g., of microfluidic design elements.

Establishing trust at the heart of blockchains themselves relies on crowd-based "skin in the game" mechanisms referred to as proof-of-work and (delegated) proof-of-stake, respectively. In the meantime, the blockchain community has created an ample ecosystem reaching beyond the social Web2.0 encompassing formalized reputation and staking schemes $^{2,39}$, idea promotion ${ }^{40}$, bounties $^{5}, \mathrm{TBCs}^{41}$ (Goro, 2018), and curation markets (de la Rouviere, 2017). They incentivize objective vetting of experts via their immutable track record on reputation and community-based validation of technological concepts.

\section{CROWDSOURCING}

\section{Project Structure}

We now outline how the previously introduced "Wisdom of the Crowds" and reputation systems trustfully and

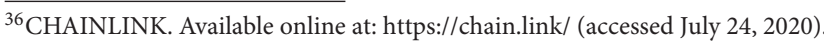

${ }^{37}$ IOTA Foundation. Available online at: https://www.iota.org/ (accessed July 24, 2020).

${ }^{38}$ Non-Fungible Token. Available online at: https://en.wikipedia.org/wiki/Nonfungible_token

${ }^{39}$ Numerai. Available online at: https://numer.ai/ (accessed August 28, 2020).

${ }^{40}$ Ideamarket.io. Available online at: https://ideamarket.io/

${ }^{41}$ Molecule.to. Available online at: https://molecule.to/ (accessed July 24, 2020).
}

transparently implemented by Blockchain technologies can be synergistically combined to organize projects on open technology platforms with the example of LoaD. As opposed to a linear project in Figure 2, in such an RTD project, as represented in Figure 4, the smart-contract and skin-in-the-game-backed open platform allows one to tap into the crowd across all stages of value creation and decision making.

Similar to architectural competitions, initial idea generation, e.g., an internal team, can be boosted by inputs from a vast pool of clever brains. Blockchain provides timestamping such IP on its unforgeable and immutable ledger, and smart contracts can establish and implement clear-cut rules for participation, e.g., on shares of future revenues or license royalties. Skin-in-the-game schemes staking cryptoassets or reputation (tokens) in prediction markets $2,5,42,43$ can then support sound planning including the required investment, which might also be raised by crowdfunding mechanisms, e.g., seigniorage and minting crypto-economical assets.

\section{Competitive Parallelization}

For the following RTD phase and the supply chain, much of the work, expertise, infrastructure, and services, at least the parts that are uncritical for the USP of the eventual product, should be crowdsourced on the basis of an open platform model.

\footnotetext{
${ }^{42}$ Stox.com. Available online at: https://www.stox.com/ (accessed July 27, 2020)

${ }^{43}$ Gnosis.io. Available online at: https://gnosis.io/ (accessed July 27, 2020).
} 


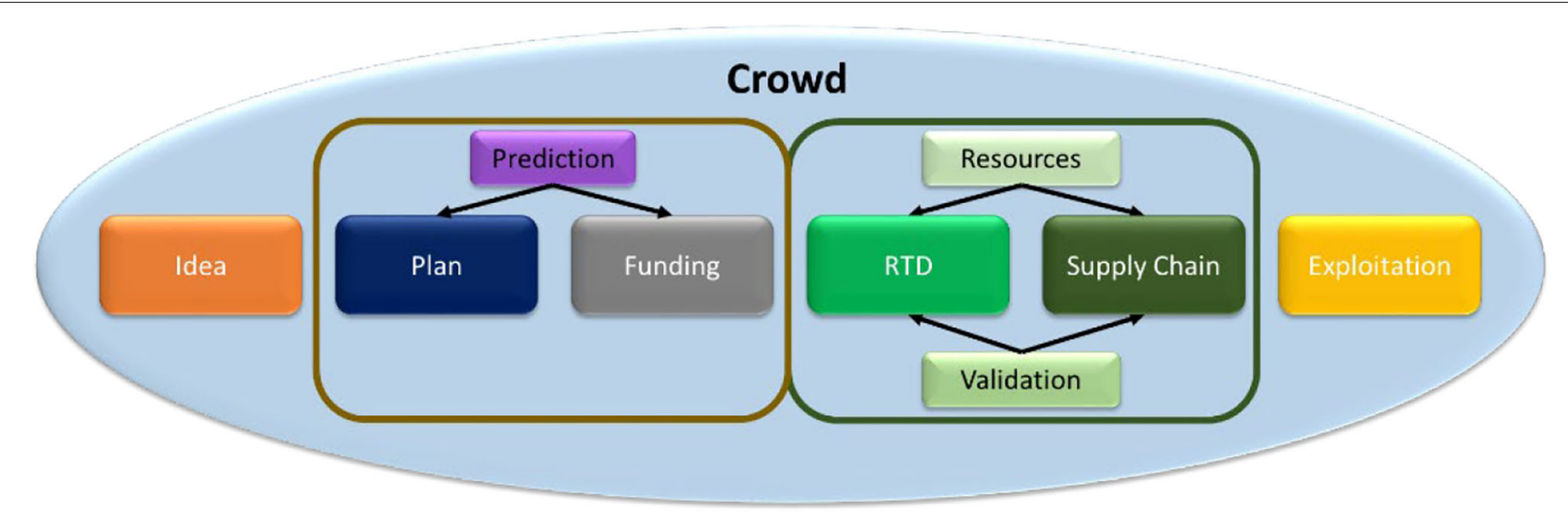

FIGURE 4 | Involvement of the "Crowd" along the entire value creation from idea to delivery and exploitation. Energized by a blockchain-implemented token economy, prediction markets for planning are backed by collective intelligence while work and validation on RTD and supply chain are crowdsourced through competitive parallelization as outlined in the green-framed box and further illustrated in Figure $\mathbf{5}$.

While trust in accompanying financial transactions is assured by "programmable money" in the form of smart contracts on the (e.g., Ethereum) blockchain, the best possible "truth" on outcomes in the physical world, e.g., as feeds for decision making algorithms called "oracles" $44,45,46$ encoded on the blockchain, is found through competitive parallelization of deliverables and their validation (Figure 5).

In more detail, the deliverable of a work package (WP) should be described, as much as possible, by objectively assessable criteria such as quantitative Key Performance Indicators (KPIs) and associated methods of their characterization. These descriptors are posted to prompt a "race" for rewards or bounties attracting offers from (independent) players. Buyers may then select a subset of these proposals for concurrent execution. Their deliverables are then evaluated and ranked, e.g., by holders of governance tokens, and then remunerated with crypto-assets according to a pre-defined, transparent scheme that is immutably recorded on the blockchain.

Buyers, workers, and validators can complement their requests or bids by blockchain enabled staking and reward schemes, e.g., in the form of fiat-convertible assets and quantified reputation, which are formally managed by smart contracts on the tamper-free and transparent DLT. Decision making for conflict resolution may be implemented by blockchain-backed arbitration mechanisms $s^{8,47}$. Overall, such competitive parallelization thus extends the peer-review process known from academic publishing by crowdsourcing of WPs to enrich intellectual contributions, the skill set, infrastructure,

\footnotetext{
${ }^{44}$ Blockchain Oracles. Available online at: https://blockchainhub.net/blockchainoracles/ (accessed July 24, 2020).

${ }^{45}$ Oracles. Available online at: https://docs.corda.net/docs/corda-os/4.5/keyconcepts-oracles.html (accessed August 10, 2020).

${ }^{46}$ The Provable ${ }^{\mathrm{TM}}$ Blockchain Oracle for Modern DApps. Available online at: https://provable.xyz/ (accessed August 10, 2020).

${ }^{47}$ Telos Blockchain Network Arbitration Rules and Procedures. Available online at: https://resources.telosfoundation.io/governance_documents/ TBNARP_Adopted_2018-10-26.pdf (accessed July 24, 2020).
}

equipment, bandwidth, and flexibility of the human resources and infrastructure available for the project.

At first glance, the parallelized approach in Figure 5 seems to be more costly than the linear scheme in Figure 3. This would certainly hold when assuming equal work efficiencies among both approaches. However, experience, especially when projects involve academic partners on public grants, tells that running a highly diverse interdisciplinary project with an internal team often leads to significant gaps in competences and delays on deliverables, especially in the technologies that reside outside the participant's main technological or commercial enablers.

To give a simplified example, crowdsourcing competence leaders at triple rate of an internal resource significantly enhances quality and accelerates delivery by a factor of 10 , so charging a given WP to three expert players in parallel is likely to deliver at roughly the same overall cost, while substantially improving quality, credibility, and speed of delivery. It is acknowledged that competitive parallelization might not bode well with traditional funding schemes, investors, and phases of projects, e.g., during seed funding of early stage start-ups.

Bestowed with the "trust" and "truth" through the blockchain and streamlining by the open platform concept, participation in RTD and supply chains is not restricted to full-fledged organizations; it rather reaches out to talent, knowledge, and workforce of non-institutionalized individuals, e.g., through "hackathons" 48 or "citizen science" 49 . Fast emerging trends like decentralized ${ }^{50}$ for making "things" (Birch, 2019), e.g., by $3 \mathrm{D}$ printing, cloud-based access to software, supercomputing, artificial intelligence (AI), Big Data solutions ${ }^{51,52}$, and real-time $5 \mathrm{G}$ communication network, are likely to further globalize and somewhat democratize value creation.

\footnotetext{
${ }^{48}$ Hackathon. Available online at: https://en.wikipedia.org/wiki/Hackathon

${ }^{49}$ Foldit. Available online at: https://fold.it/ (accessed July 24, 2020).

${ }^{50}$ Fab Labs (2020). Available online at: https://www.fablabs.io/ (accessed July 24, 2020).

${ }^{51}$ AWS - Amazon Web Services. Available online at: https://aws.amazon.com/

${ }^{52}$ Google Cloud. Available online at: https://cloud.google.com/
} 


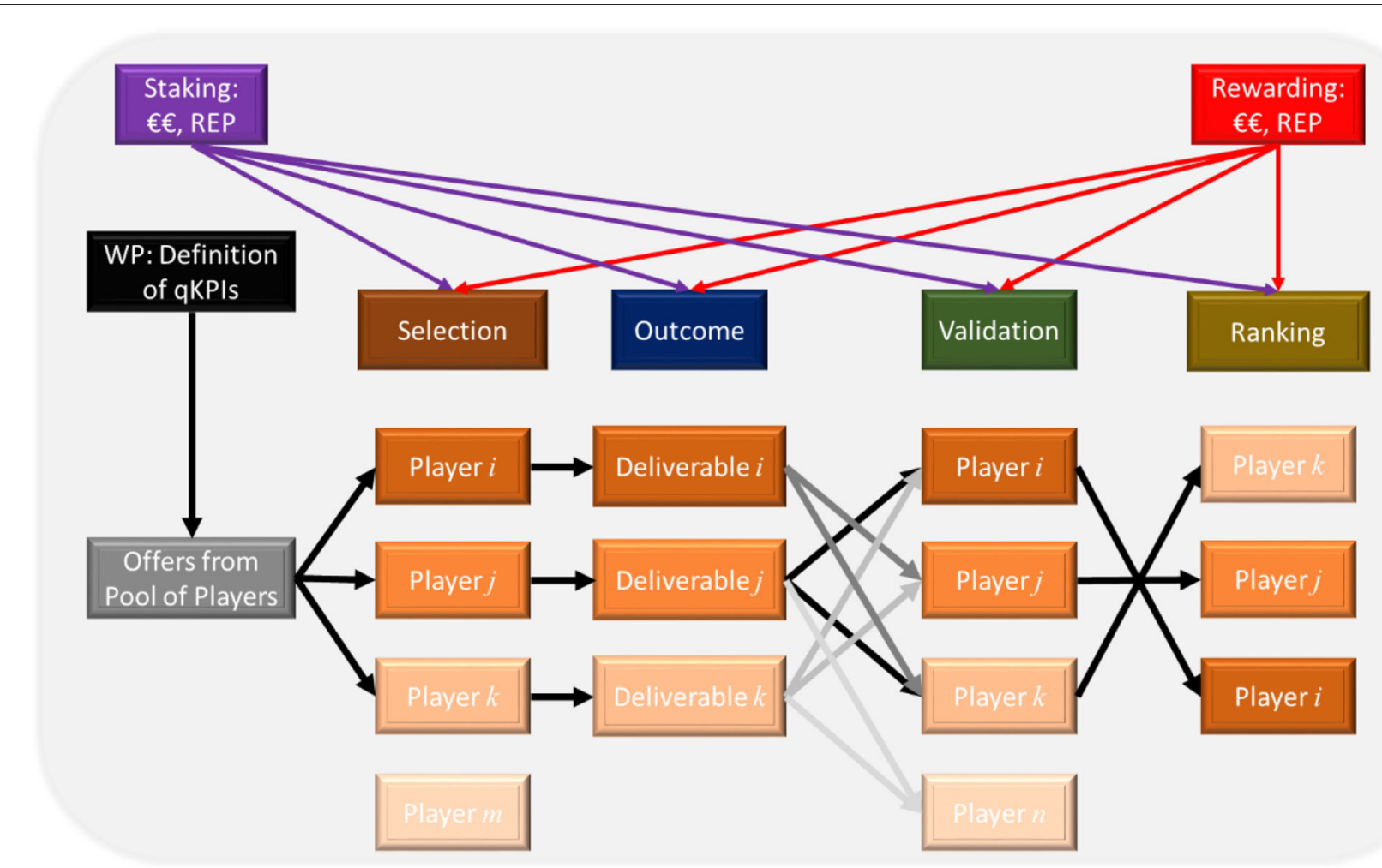

FIGURE 5 | Competitive parallelization. A system integrator or buyer crowdsources the work, e.g., on RTD or manufacture from independent players. The buyer selects a subgroup of players according to their offers. The outcomes are ranked, as much as possible, by a validation panel according to quantitative Key Performance Indicators. Bidders can increase their chance of acceptance by staking while quality work is rewarded by assets and reputation.

\section{TRENDS AND CHALLENGES}

\section{Platform Strategies for Supply Chain Resilience, Responsiveness, and Reconfigurability}

The blockchain-backed open platform concept follows strong movements in globalization and regulation, in addition to advances in digitalization and data analytics, which are generating business opportunities in terms of novel value creation $^{53}$. These drivers have formed an environment in which many firms are encountering new challenges and opportunities in traditional supply chain practices, for instance, in enhancing their resilience, responsiveness, and reconfigurability. A common thread recently emphasized by leading international multinational corporations (e.g., Cisco, Coca-Cola, Jaguar, and Land Rover) is the need to connect, network, and collaborate across supply chains-in developing a "cleverer together" operating philosophy, in designing supply chains to be more agile and customer-focused, in exploiting the potential of digitalization (e.g., blockchain for governance), and in addressing the environmental impact of existing supply chain designs (Harrington, 2015). This is now further influenced by the complexities of the "new normal," as such firms struggle to

${ }^{53}$ UNCTAD - United Nations Conference on Trade and Development. Available online at: https://unctad.org/ assess and rebuild their global supply chains after COVID-19 (Betti and Ni, 2020).

One area of focus is to develop open platform strategies for (re-)distributed manufacturing (RDM), i.e., "the ability to personalize product manufacturing and deployment at multiple scales and locations, be it at the point of consumption, sale, or within production sites" (Srai et al., 2016b) to promote supply chain resilience, responsiveness, and reconfigurability. RDM can also have a democratizing effect on participation at a socio-economic level (Srai et al., 2016a). Here, new "Circular Economy 4.0" operating principles have been developed that capture the interplay between digital technologies and circular supply chain designs based on centralized-semicentralized-decentralized configurations (Tsolakis et al., 2020). In promoting free access to, e.g., "asset libraries" of manufacturing processes and simulation methods, these configurations and operating principles lend themselves to open technology platforms for the crowdsourcing of supply chain including RTD, through Blockchain.

This is in line with moves toward interdisciplinary approaches involving "innovation ecosystems" of diverse actors-ranging from skilled individuals (the "citizen scientist"; the "garage entrepreneur") and a new type of freelance researcher to more emerging small and medium enterprises (SMEs) and well-established firms. Economic activity does not necessarily translate to direct support of "micro-innovators," for example, 
in do-it-yourself (DIY) biotechnology-type RTD contexts ${ }^{54}$. Hence, open platform strategies can advance the emergence of a network of entrepreneur archetypes to collectively solve intractable challenges, by drawing on the philosophies of "open science" (Smart et al., 2019) and "collective intelligence" (Malone and Bernstein, 2015).

Our blockchain-backed open platform concept features important aspects of both RDM and the "innovation ecosystem," such as providing access to local resources, exemplified by enhanced user participation across technology development, fabrication, and supply. These mechanisms are typically enabled by digitalization, virtualization, and new production (and analytical) technologies. We extend RDM by crowdsourcing upfront RTD and inclusion of non-corporate entities, e.g., empowering citizen science communities to avail of a resilient supply chain network of assets.

\section{Challenges and Solutions}

There are still various bottlenecks that stymie a seminal breakthrough of blockchain technologies. In the public eye, the volatility of cryptocurrencies represents a critical downside; meanwhile, a number of stablecoins have been issued, which are hard- or soft-pegged to fiat currencies ${ }^{20,55,56,57,58}$. Also, solutions to increase scalability, transaction throughput ${ }^{59,60}$ (Bitcoin Cash, 2020; Bitcoin SV, 2020; Mearian, 2020), interoperability ${ }^{27,61}$, and compliance with financial regulators (Hussey, 2019; The LAO, 2019) have been developed.

Scamming, exploits, malicious attacks, and poor governance constitute major setbacks for any project. Blockchain has already suffered, e.g., through the notorious hack of "The DAO" (Đ), the biggest crowdfunded project at its time having raised over $\$ 150$ million from its more than 10,000 supporters (Siegel, 2016; Vigna, 2016) in 2016. Since then, smart contract security and other mitigation techniques have been massively improved, and even larger projects and DAOs raising several billion dollars have been launched ${ }^{62}$ (Rooney, 2018).

Similarly, the "code is law" paradigm propagated by some hardcore blockchain communities might clash with legislation and may undermine contingency plans usually required to mitigate the fall-out of unintended events, for instance, related to program bugs and abuse. More recent technologies and networks, such as Telos ${ }^{63}$, implement liquid democracy

\footnotetext{
${ }^{54}$ DITOS Consortium and WeObserve Consortium: Making Citizen Science work: Innovation Management for Citizen Science, in DITOS Policy Brief 6. (2019).

${ }^{55}$ USD Coin. Available online at: https://www.centre.io/usdc (accessed July 24, 2020).

${ }^{56}$ Anchor. Available online at: https://theanchor.io/ (accessed July 24, 2020).

${ }^{57}$ eToro (2020). Available online at: https://www.etoro.com/news-and-analysis/ market-insights/what-role-will-stablecoins-play-in-crypto-mass-adoption/ (accessed January 13, 2020).

${ }^{58}$ Tether (2020). Available online at: https://tether.to/ (accessed July 24, 2020).

${ }^{59}$ Lightning Network. Available online at: https://lightning.network/ (accessed July 24, 2020).

${ }^{60}$ TRON (2020). Available online at: https://tron.network/ (accessed July 24, 2020).

${ }^{61}$ Bitcoin (2020). Available online at: https://bitcoinmagazine.com/guides/whatare-atomic-swaps (accessed July 24, 2020).

${ }^{62}$ Block one. Available online at: https://block.one/ (accessed July 24, 2020).

${ }^{63}$ Telos (2020). Telos. Available online at: https://www.telosfoundation.io/ (accessed July 24, 2020).
}

principles and utilize readily upgradable smart contracts, and token holders appoint arbitrators ${ }^{38,64}$.

Most USPs of blockchain application are difficult to convey to the wider public, and participation often goes through user interfaces, such as decentralized applications ("DApps") 65,66, which may only be handled by possessing a certain level of technological understanding. This limits the creation of a critically sized user base for which the operation of blockchain concepts make sense (Zhu and Iansiti, 2019). For similar reasons, it is difficult to provide test beds including a larger number of players that sufficiently represent all facets of the real-world user base (Harrington et al., 2018; Skowronski and Benton, 2018). There is good progress on simulation tools ${ }^{67}$.

Furthermore, institutional anchoring and compliance with existing legal frameworks, e.g., on corporate structure, equity, and taxation, are, for the most part, not solved in a satisfactory fashion, yet $^{68}$ (The LAO, 2019). Still, there are various governments evaluating their benefits and options for their legal embedding $^{69}$ (see text footnote ${ }^{24,70}$ ).

With the growing awareness for protecting the global ecosphere, there is somewhat valid public concern regarding the sizeable power consumption underpinning the protection of first-generation blockchains by "Proof of Work"; alternative "Proof-of-Authority" 25, "Proof of Stake," or more sophisticated "Delegated Proof of Stake"71, whether in public or permissioned blockchains, decisively reduce the environmental impact and aim to curb occasionally surging utility fees (O'Neal, 2020). Also, scalability issues that seem to be somewhat intrinsic to many first-generation blockchain technologies are well-known and addressed at high priority, e.g., through transient compartmentalization ("sharding") (Mearian, 2020), side chaining (Singh et al., 2020), and offline operation ("Lightning network") ${ }^{46}$.

\section{SUMMARY, CONCLUSIONS, AND OUTLOOK}

This paper synergistically combines a blockchain-endowed token economy for finding trust and truth rooted in skinin-the-game, collective intelligence, prediction markets, and competitive parallelization mechanisms with an open

\footnotetext{
${ }^{64}$ Telos user's guide. Available online at: https://medium.com/telos-foundation/ telos- user-guide- understanding-telos-arbitration-111e2397244b (accessed July 24, 2020).

${ }^{65}$ Decentralized Application. Available online at: https://en.wikipedia.org/wiki/ Decentralized_applicationDapp.com. Available online at: https://www.dapp.com/ search/Marketplace (accessed July 24, 2020).

${ }^{66}$ MetaCartel. Available online at: https://www.metacartel.org/ (accessed August 17, 2020).

${ }^{67}$ BlockScience. Available from: https://block.science/.

${ }^{68}$ SEC (2017). Available online at: https://www.sec.gov/news/press-release/2017131 (accessed July 24, 2020).

${ }^{69}$ Bundesblock (2020). BLOCKCHAIN BUNDESVERBAND. Available online at: https://bundesblock.de/ (accessed July 24, 2020).

${ }^{70}$ Government Blockchain Association (GBA) (2020). Available online at: https:// www.gbaglobal.org/ (accessed July 24, 2020).

${ }^{71}$ DPoS - Delegated Proof of Stake. Available online at: https://en.bitcoinwiki.org/ wiki/DPoS (accessed July 24, 2020).
} 
platform strategy. The novel approach for value creation and supply chain formation is exemplified by the LoaD platform where it harmonizes technology development for efficient crowdsourcing of ideas, RTD, validation, infrastructure, equipment, processes, and services from a wide range of participants including corporations, institutions, and individuals. The strategy is particularly suited for accelerating and de-risking commercialization of highly interdisciplinary applications by smaller players requiring early investment and fast innovation for rapid market entry.

In addition to their implementation by companies or research organizations, such RTD projects may also be managed in the form of a DAO that is entirely run by a crowd of stakeholders through blockchain-enabled tools for governance and arbitration. Apart from commercial objectives, such DAOs have also been suggested for grassroots-driven non-for-profit initiatives on global Commons ${ }^{72}$, e.g., in the context of disaster prevention like pandemics or "Saving the Planet" (Ducrée et al., 2020). They also well-align with trends such as new models of collaboration and RDM, globalization, democratization,

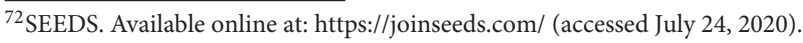

\section{REFERENCES}

Andersson, P., Jesson, G., Kylberg, G., Ekstrand, G., and Thorsen, G. (2007). Thorsen parallel nanoliter microfluidic analysis system. Anal. Chem. 79, 4022-4030. doi: 10.1021/ac061692y

Baldwin, M. (2018). Scientific autonomy public accountability and the rise of "Peer Review" in the cold war united states. Am. Inst. Phys. 109, 538-558. doi: $10.1086 / 700070$

Bartling, S. (2016). Blockchain for Science. Available online at: https://www. blockchainforscience.com/ (accessed July 24, 2020).

Becker, H. (2010). Collective wisdom. Lab. Chip. 10, 1351-1354. doi: $10.1039 / \mathrm{c} 004239 \mathrm{k}$

Betti, F., and Ni, J. (2020). How China can Rebuild Global Supply Chain Resilience After COVID-19. Available online at: https://www.weforum.org/agenda/2020/ 03/coronavirus-and-global-supply-chains/

Birch, J. (2019). Blockchain and 3D printing are reinventing aerospace supply chains. Available online at: https://cointelegraph.com/news/ blockchain-and-3d-printing-are-reinventing-aerospace-supply-chains (accessed September 8, 2020).

Bitcoin Cash (2020). Bitcoin Cash - Peer-to-Peer electronic cash. Available online at: https://www.bitcoincash.org/ (accessed July 24, 2020).

Bitcoin SV (2020). Bitcoin SV is the Original Bitcoin. Available online at: https:// bitcoinsv.io/ (accessed July 24, 2020)

Böning, J., Mark, D., Lutz, S., Faltin, B., Focke, M., Karle, M., et al. (2008). "Labon-a-Chip Foundry Service: a systematic approach to the development of centrifugal microfluidic technologies," in Actuator 08, Conference Proceedings, 814-817.

Böttcher, E. (2018). What I Talk About When I Talk About Platforms. Available online at: https://martinfowler.com/articles/talk-about-platforms.html

Brennan, D., Coughlan, H., Clancy, E., Dimov, N., Barry, T., and Kinahan, D., (2017). Development of an on-disc isothermal in vitro amplification and detection of bacterial RNA. Sens. Actuators B Chem. 239, 235-242. doi: 10.1016/j.snb.2016.08.018

Brownstein, J. S., and Freifeld, C. C. (2007). HealthMap: the development of automated real-time internet surveillance for epidemic intelligence. Euro Surveill. 12:E071129.5 doi: 10.2807/esw.12.48.03322-en

Burger, R., Kurzbuch, D., Gorkin, R., Kijanka, G., Glynn, M., McDonagh, C., et al. (2015). An integrated centrifugo-opto-microfluidic platform for arraying, decentralization of value creation, data ownership, access and exploitation, and the future or work.

With all prospects, the advancement, validation, and convergence of its underlying technologies, packaging the resulting potential benefits into a compelling message to the general, presently widely uninformed, confused or just apathetic public is urgently required. Also tapping into decisive economies-of-scale effects still represents a major bottleneck to the wider-scale breakthrough of blockchain beyond DeFi.

\section{DATA AVAILABILITY STATEMENT}

The original contributions presented in the study are included in the article/supplementary material, further inquiries can be directed to the corresponding author/s.

\section{AUTHOR CONTRIBUTIONS}

JD developed idea and authoring pf manuscript. TH made major contribution from a business and supply chain point of view. MG, RW, ME and SB advised on blockchain technologies. All authors contributed to the article and approved the submitted version.

analysis, identification and manipulation of individual cells. Lab Chip. 15, 378-81. doi: 10.1039/C4LC01002G

Buterin, V. (2014). White Paper. Ethereum/wiki Wiki GitHub. Available online at: https://github.com/ethereum/wiki/wiki/White-Paper (accessed July 24, 2020).

Clime, L., Brassard, D., Geissler, M., and Veres, T. (2015). Active pneumatic control of centrifugal microfluidic flows for lab-on-a-chip applications. Lab Chip 15, 2400-2411. doi: 10.1039/C4LC01490A

Clime, L., Daoud, J., Brassard, D., Malic, L., Geissler, M., and Veres, T. (2019). Active pumping and control of flows in centrifugal microfluidics. Microfluidics Nanofluidics 23:29. doi: 10.1007/s10404-019-2198-x

Craig, B. R., and Kachovec, J. (2019). "Economic commentary," in Bitcoin's Decentralized Decision Structure. (Federal Reserve Bank of Cleveland), 1-5. doi: 10.26509/frbc-ec-201912

de la Rouviere, S. (2017). Introducing Curation Markets: Trade Popularity of Memes and Information (with code)! Available online at: https://medium. com/@simondlr/introducing-curation-markets-trade-popularity-of-memesinformation-with-code-70bf6fed9881 (accessed July 24, 2020).

Delgado, S. M. T., Kinahan, D. J., Julius, L. A. N., Mallette, A., Ardila, D. S., Mishra, R., et al. (2018). Wirelessly powered and remotely controlled valve-array for highly multiplexed analytical assay automation on a centrifugal microfluidic platform. Biosens. Bioelectron. 109, 214-223. doi: 10.1016/j.bios.2018. 03.012

Dimov, N., Gaughran, J., Mc Auley, D., Boyle, D., Kinahan, D. J., and Ducrée, J. (2014). "Centrifugally automated solid-phase purification of RNA," in 2014 IEEE 27th International Conference on Micro Electro Mechanical Systems (MEMS) (San Francisco: IEEE), 260-263. doi: 10.1109/MEMSYS.2014.6765625

Ducrée, J. (2019). Efficient development of integrated Lab-On-A-Chip systems featuring operational robustness and nanufacturability. Micromachines 10:866. doi: $10.3390 / \mathrm{mil} 10120886$

Ducrée, J. (2020). Reliability analysis and optimization towards highly multiplexed lab-on-a-disc systems. J. Microelectromechanical Systems. doi: 10.3389/fbloc.2020.00033

Ducrée, J., Etzrodt, M., Gordijn, B., Gravitt, M., Bartling, S., Walshe, R., et al. (2020). Blockchain for organising effective grass-roots actions on a global commons: saving the planet. Front. Blockchain 3:33.

Ducrée, J., Haeberle, S., Lutz, S., Pausch, S., Stetten, F. V., and Zengerle, R. (2007). The centrifugal microfluidic bio-disk platform. J. Micromech. Microeng. 17, S103-S115. doi: 10.1088/0960-1317/17/7/S07 
Ducrée, J., and Zengerle, R. (2004). FlowMap - Microfluidics Roadmap for the Life Sciences. Norderstedt: Books on Demand GmbH.

Edmondson, B. (2020). How Bitcoin and Blockchain Are Changing Crowdfunding. Available online at: https://www.thebalance.com/how-bitcoin-andblockchain-is-changing-crowdfunding- 4173837 (accessed July 24, 2020).

Ersland, P., and Somisetty, S. (2012). Reliability validation of compound semiconductor foundry processes. Microelectron. Reliabil. 52, 2210-2214. doi: 10.1016/j.microrel.2012.07.004

García-Cordero, J. L., Basabe-Desmonts, L., Ducrée, J., and Ricco, A. J. (2010). Liquid recirculation in microfluidic channels by the interplay of capillary and centrifugal forces. Microfluidics Nanofluidics. 9, 695-703. doi: 10.1007/s10404-010-0585-4

Godino, N., Comaskey, E., Gorkin, R., and Ducrée, J. (2012). "Centrifugally enhanced paper microfluidics," in 2012 IEEE 25th International Conference on Micro Electro Mechanical Systems (MEMS). (IEEE: Paris, France) doi: 10.1109/MEMSYS.2012.6170187

Gorkin, R. 3rd, Nwankire, C. E., Gaughran, J., Zhang, X., Donohoe, G. G., Rook, M., et al. (2012). Centrifugo-pneumatic valving utilizing dissolvable films. Lab Chip. 12, 2894-902. doi: 10.1039/c2lc20973j

Goro, J. (2018). Token Bonding Curves Explained. Available online at: https:// medium.com/coinmonks/token-bonding-curves-explained-7a9332198e0e (accessed July 24, 2020)

Govindan, K., Shankar, M., and Kannan, D. (2018). Supplier selection based on corporate social responsibility practices. Int. J. Product. Econ. 200, 353-379. doi: 10.1016/j.ijpe.2016.09.003

Grieves M., and Digital, V. J. (2017). "Digital twin: mitigating unpredictable, undesirable emergent behavior in complex systems," in Transdisciplinary Perspectives on Complex Systems (Cham: Springer), 85-113.

Halton, C. (2019). Prediction Market. Available online at: https://www. investopedia.com/terms/p/prediction-market.asp (accessed July 24, 2020).

Harrington, T. (2015). Connecting the Unconnected: New Thinking on NextGeneration Supply Chains. If $M$ Rev. University of Cambridge. Available online at: https://www.ifm.eng.cam.ac.uk/news/connecting-the-unconnectednew-thinking-on-next-generation-supply-chains/

Harrington, T., and Srai, J. (2016). Understanding stages of supply network emergence in technology commercialisation. Int. J. Manufact. Technol. Manag. 33, 4-36. doi: 10.1504/IJMTM.2016.10000001

Harrington, T., and Zhang, Y. (2017). Supply network evolution in emerging industries. Int. J. Manufact. Technol. Manag. 31, 1-3.

Harrington, T. S., Joglekar, N. R., and Srai, J. S. (2018). Digitalisation of Development and Supply Networks: Sequential and Platform-Driven Innovations. Available online at: https://ssrn.com/abstract=3238907

Hill, S., and Ready-Campbell, N. (2011). Expert Stock Picker: The Wisdom of (Experts in) Crowds. Available online at: http://repository.upenn.edu/oid_ papers/72?utm_source=repository.upenn.edu\%2Foid_papers\%2F72\&utm_ medium $=$ PDF\&utm_campaign $=$ PDFCoverPages

Hills, S. B., and Sarin, S. (2015). From market driven to market driving: an alternate paradigm for marketing in high technology industries. J. Market. Theory Pract. 11, 13-24. doi: 10.1080/10696679.2003.11658498

Honda, N., Lindberg, U., Andersson, P., Hoffman, S., and Takei, H. (2005). Simultaneous multiple immunoassays in a compact disc-shaped microfluidic device based on centrifugal force. Clin. Chem. 51, 1955-1961. doi: 10.1373/clinchem.2005.053348

Hussey, M. (2019). What is Tokenomics? Available online at: https://decrypt.co/ resources/tokenomics

Jaworski, B., Kohli, A. K., and Sahay, A. (2000). Market-driven versus driving markets. J. Acad. Market. Sci. 28, 45-54. doi: 10.1177/0092070300281005

Johnson, R. D., Badr, I. H. A., Barrett, G., Lai, S. Y., Lu, Y. M., Madou, M. J., et al. (2001). Development of a fully integrated analysis system for ions based on ion-selective optodes and centrifugal microfluidics. Anal. Chem. 73, 3940-3946. doi: $10.1021 /$ ac0102819

Khan, M. U., Xing, Y., Ye, Y., and Bogaerts, W. (2019). Photonic integrated circuit design in a foundry+fabless ecosystem. IEEE J. Select. Top. Quant. Electron. 25, 1-14. doi: 10.1109/JSTQE.2019.2918949

Kinahan, D. J., Burger, R., Vembadi, A., Kilcawley, N. A., Lawlor, D., Glynn, M. T., et al. (2015). "Baking-powder driven centripetal pumping controlled by eventtriggering of functional liquids," in 2015 28th IEEE International Conference on Micro Electro Mechanical Systems (MEMS 2015), (Estoril: IEEE), 504-507. doi: 10.1109/MEMSYS.2015.7051002

Kinahan, D. J., Early, P. L., Vembadi, A., MacNamara, E., Kilcawley, N. A., Glennon, T., et al. (2016). Xurography actuated valving for centrifugal flow control. Lab Chip. 16, 3454-3459. doi: 10.1039/C6LC00568C

Kinahan, D. J., Kearney, S. M., Dimov, N., Glynn, M. T., and Ducree, J. (2014). Event-triggered logical flow control for comprehensive process integration of multi-step assays on centrifugal microfluidic platforms. Lab. Chip. 14, 2249-58. doi: 10.1039/C4LC00380B

Klapperich, C. M. (2009). Microfluidic diagnostics: time for industry standards. Expert Rev. Med. Devices 6, 211-3. doi: 10.1586/erd.09.11

Krauss, S.T., Woolf, M. S., Hadley, K. C., Collins, N. M., Nauman, A. Q., and Landers, J.P. (2019). Centrifugal microfluidic devices using low-volume reagent storage and inward fluid displacement for presumptive drug detection. Sens. Actuators B Chem. 284, 704-710. doi: 10.1016/j.snb.2018.12.113

Kumar, N., Scheer, L., and Kotler, P. (2000). From market driven to market driving. Eur. Manag. J. 18, 129-142. doi: 10.1016/S0263-2373(99)00084-5

Lasch, R., Kopfer, H., and Janker, C. G. (2005). Supplier selection and controlling using multivariate analysis. Int. J. Phys. Distrib. Logistics Manag. 35, 409-425. doi: $10.1108 / 09600030510611648$

Leonhard, R. (2019). Decentralized Finance on the Ethereum Blockchain. Available online at: https://ssrn.com/abstract $=3359732$

Madou, M. J., and Kellogg, G. J. (1998). The LabCD (TM): a centrifuge-based microfluidic platform for diagnostics. Syst. Technol. Clin. Diagn. Drug Discov. 3259, 80-93. doi: 10.1117/12.307314

Malic, L., Zhang, X., Brassard, D., Clime, L., Daoud, J., Luebbert, C., et al. (2015). Polymer-based microfluidic chip for rapid and efficient immunomagnetic capture and release of Listeria monocytogenes. Lab Chip 15, 3994-4007. doi: 10.1039/C5LC00852B

Malone, T., and Bernstein, M. (2015). Handbook of Collective Intelligence. Cambridge: MIT Press.

Mark, D., Metz, T., Haeberle, S., Lutz, S., Ducrée, J., Zengerle, R., et al. Centrifugopneumatic valve for metering of highly wetting liquids on centrifugal microfluidic platforms. Lab Chip. (2009) 9, 3599-3603. doi: 10.1039/b914415c

McKenna, M. (2020). How ProMED Crowdsourced the Arrival of Covid-19 and SARS. The Low-Tech Site Run by Health Experts Collects Reports of New Diseases in Real Time. They've Got a Shoestring Budget-and a Stunning Track Record. Available online at: https://www.wired.com/story/how-promedcrowdsourced-the-arrival-of-covid-19-and-sars/

McRae, M. P., Simmons, G. W., Christodoulides, N. J., Lu, Z., Kang, S. K., Fenyo, D., et al. (2020). Clinical decision support tool and rapid point-of-care platform for determining disease severity in patients with COVID-19. Lab Chip. 20, 2075-2085. doi: 10.1039/D0LC00373E

Mearian, L. (2020). Sharding: What it is and Why Many Blockchain Protocols Rely on it. Available online at: https://www.computerworld.com/article/3336187/ sharding-what-it-is-and-why-so-many-blockchain-protocols-rely-on-it. html (accessed July 24, 2020).

Miller, A. (2016). Ethereum Isn't Turing Complete and it Doesn't Matter Anyway. Available online at: https://media.consensys.net/ethereum-isntturing-complete-and-it-doesn-t-matter-anyway-625061294d3c (accessed July $24,2020)$.

Mishra, R., Alam, R., Kinahan, D. J., Anderson, K., and Ducrée, J. (2015) "Lipophilic-membrane based routing for centrifugal automation of heterogeneous immunoassays," in 2015 28th IEEE International Conference on Micro Electro Mechanical Systems (MEMS 2015). (Estoril: IEEE), 523-526. doi: 10.1109/MEMSYS.2015.7051007

Montoya, T. (2020) Nonfungible Tokens Could Change the Way We Own Things. Available online at: https://cointelegraph.com/news/nonfungibletokens-could-change-the-way-we-own-things

Muffatto, M. (1999). Introducing a platform strategy in product development. Int. J. Product. Econ. 60-61, 145-153. doi: 10.1016/S0925-5273(98)00173-X

Nakamoto, S. (2009). Bitcoin: A Peer-to-Peer Electronic Cash System. Available online at: https://metzdowd.com (accessed May 24, 2009).

O'Neal, S. (2020). ETH Miners Will Have Little Choice Once Ethereum 2.0 Launches With PoS. Available online at: https://cointelegraph.com/news/eth-minerswill-have-little-choice-once-ethereum-20-launches-with-pos (accessed June 16, 2020; August 18, 2020). 
Rooney, K. A. (2018). Blockchain Start-Up Just Raised \$4 Billion Without a Live Product. 01/06/2018 Available online at: https://www.cnbc.com/2018/05/ 31/a-blockchain-start-up-just-raised-4-billion-without-a-live-product.html (accessed July 24, 2020).

Rouviere, S. D. L. (2017). A Practical Example of Curation Markets: An \#ethtrader Token for Curating Good Market Analysis. Available online at: https://media.consensys.net/a-practical-example-of-curation-markets-anethtrader-token-for-curating-good-market-analysis- $6 \mathrm{f} 6 \mathrm{f} 340 \mathrm{c} 6916$

Santos, F. M., and Eisenhardt, K. M. (2009). Constructing markets and shaping boundaries: entrepreneurial power in nascent fields. JSTOR 52, 643-671. doi: 10.5465/amj.2009.43669892

Sarasvathy, S. D. (2001). Causation and effectuation: toward a theoretical shift from economic inevitability to entrepreneurial contingency. Acad. Manag. Rev. 26, 243-263. doi: 10.2307/259121

Schembri, C. T., Burd, T. L., Kopfsill, A. R., Shea, L. R., and Braynin, B. (1995). Centrifugation, and capillarity integrated into a multiple analyte wholeblood analyzer. J. Autom. Chem. 17, 99-104. doi: 10.1155/S14639246950 00174

Schembri, C. T., Ostoich, V., Lingane, P. J., Burd, T. L., and Buhl, S. N. (1992). Portable simultaneous multiple analyte whole-blood analyzer for point-of-care testing. Clin. Chem. 38, 1665-1670. doi: 10.1093/clinchem/38.9. 1665

Sebastiao, H. J., and Golicic, S. (2008). Supply chain strategy for nascent firms in emerging technology markets. J. Bus. Logistics 29, 75-91. doi: 10.1002/j.2158-1592.2008.tb00069.x

Sharma, R. (2019). Three People Who Were Supposedly Bitcoin Founder Satoshi Nakamoto. Available online at: https://www.investopedia.com/tech/threepeople-who-were-supposedly-bitcoin-founder-satoshi-nakamoto/ (accessed June 25, 2019; August 24, 2020),

Siegel, D. (2016). Understanding The DAO Attack. Available online at: https://www. coindesk.com/understanding-dao-hack-journalists (accessed July 24, 2020).

Singh, A., Click, K., Parizi, R. M., Zhang, Q., Dehghantanha, A., Choo, K. R., et al. (2020). Sidechain technologies in blockchain networks: an examination and state-of-the-art review. J. Netw. Comput. Appl. 149:102471. doi: $10.1016 /$ j.jnca.2019.102471

Singh, N. (2019). Introduction to Permissioned Blockchains. Available online at: https://101blockchains.com/permissioned-blockchain/ (accessed August 25, 2020).

Skowronski, K., and Benton, W. C. (2018). The influence of intellectual property rights on poaching in manufacturing outsourcing. Product. Operat. Manag. 27, 531-552. doi: 10.1111 poms. 12813

Smart, P., Holmes, S., Lettice, F., Pitts, F. H., Zwiegelaar, J. B., Schwartz, G., et al. (2019). Open science and open innovation in a sociopolitical context: knowledge production for societal impact in an age of post-truth populism. R\&D Manag. 49, 279-297. doi: 10.1111/radm. 12377

Srai, J. S., Harrington, T. S., and Tiwari, M. K. (2016a). Characteristics of redistributed manufacturing systems: a comparative study of emerging industry supply networks. Int. J. Product. Res. 54, 6936-6955. doi: 10.1080/00207543.2016.1214765

Srai, J. S., Kumar, M., Graham, G., Phillips, W., Tooze, J., Ford, S., et al. (2016b). Distributed manufacturing: scope, challenges and opportunities. Int. J. Product. Res. 54, 6917-6935. doi: 10.1080/00207543.2016. 1192302

Status of the Microfluidics Industry (2019). Yole Développement. Available online at: http://www.yole.fr/MicrofluidicsIndustry_2019update.aspx

Stavis, S. M. (2012). A glowing future for lab on a chip testing standards. Lab Chip. 12, 3008-11. doi: 10.1039/c2lc40511c

Steigert, J., Haeberle, S., Brenner, T., Muller, C., Steinert, C. P., Koltay, P., et al. (2007). Rapid prototyping of microfluidic chips in COC. J. Micromech. Microeng. 17, 333-341. doi: 10.1088/0960-1317/17/2/020
Suberg, W. (2020). Billionaire Investor Tim Draper Quit Stocks for Bitcoin 6 Months Ago. Available online at: https://cointelegraph.com/news/billionaire-investortim-draper-quit-stocks-for-bitcoin-6-months-ago (accessed July 24, 2020).

Surowiecki, J. (2004). The Wisdom of Crowds: Why the Many are Smarter than the Few and How Collective Wisdom Shapes Business, Economies, Societies, and Nations. Random House.

Tan, B. J., Brown, M., and Pope, N. (2017). The role of respect in the effects of perceived ad interactivity and intrusiveness on brand and site. J. Market. Commun. 25, 288-306. doi: 10.1080/13527266.2016. 1270344

Tantra, R., van Heeren, H., and Jarman, J. (2016). Role of standard documents in advancing the standardization of microfluidics connectors. J. Micro/Nanolithogr. MEMS MOEMS 15:020501. doi: 10.1117/1.JMM.15.2.020501

The LAO (2019). The LAO: A For-Profit, Limited Liability Autonomous Organization. Medium.com. Available online at: https://medium. com/openlawofficial/the-lao-a-for-profit-limited-liability-autonomousorganization-9eae89c9669c

Thompson, B. L., Birch, C., Nelson, D. A., Li, J., DuVall, J. A., Le Roux, D., et al. (2016). A centrifugal microfluidic device with integrated gold leaf electrodes for the electrophoretic separation of DNA. Lab Chip 16, 4569-4580. doi: 10.1039/C6LC00953K

Tsolakis, N., Harrington, T. S., and Srai, J. (2020). Digital supply network design: a circular economy 4.0 decision-making system for real-world challenges. Product. Plan. Control. doi: 10.17863/CAM.51859

Tymm, C., Zhou, J., Tadimety, A., Burklund, A., and Zhang, J. X. J. (2020). Scalable COVID-19 detection enabled by lab-on-chip biosensors. Cell. Mol. Bioeng. 13, 313-329. doi: 10.1007/s12195-020-00642-z

van Heeren, H. (2012). Standards for connecting microfluidic devices? Lab Chip. 12, 1022-5. doi: 10.1039/c2lc20937c

Vigna, P. (2016). Chiefless company rakes in more than $\$ 100$ million - group called DAO is running itself via computer code. Wall Street J. Available online at: https://www.wsj.com/articles/chiefless-company-rakes-in-more-than-100million-1463399393 (accessed July 24, 2020).

Yaga, D., Mell, P., Roby, N., and Scarfone, K. (2018). Blockchain Technology Overview. NIST Report. doi: 10.6028/NIST.IR.8202

Yoon, D., and Youn, S. (2016). Brand experience on the website: its mediating role between perceived interactivity and relationship quality. J. Interact. Advert. 16, 1-15. doi: 10.1080/15252019.2015.1136249

Zhu, F., and Iansiti, M. (2019). Why Some Platforms Thrive and Others Don't. Available online at: https://hbr.org/2019/01/why-some-platforms-thrive-andothers-dont (accessed July 24, 2020).

Zhuang, J., Yin, J., Lv, S., Wang, B., and Mu, Y. (2020). Advanced "lab-on-a-chip" to detect viruses - current challenges and future perspectives. Biosens. Bioelecton. 163:112291. doi: 10.1016/j.bios.2020.112291

Conflict of Interest: ME was employed at Akasha Foundation. SB was sole proprietor and owner of Blockchain for Science GmbH. MG was sole proprietor and owner of Digital Scarcity LLC.

The remaining authors declare that the research was conducted in the absence of any commercial or financial relationships that could be construed as a potential conflict of interest.

Copyright (c) 2020 Ducrée, Gravitt, Walshe, Bartling, Etzrodt and Harrington. This is an open-access article distributed under the terms of the Creative Commons Attribution License (CC BY). The use, distribution or reproduction in other forums is permitted, provided the original author(s) and the copyright owner(s) are credited and that the original publication in this journal is cited, in accordance with accepted academic practice. No use, distribution or reproduction is permitted which does not comply with these terms. 